\title{
Left carinal pneumonectomy using left bronchostomy: A novel technique of crossfield intubation
}

\author{
Takahiro Nakajima, MD, PhD, Shigetoshi Yoshida, MD, PhD, and Ichiro Yoshino, MD, PhD, Chiba, Japan
}

\footnotetext{
From the Department of General Thoracic Surgery, Graduate School of Medicine, Chiba University, Chiba, Japan. Disclosures: T.N. received honoraria and lecture fees from Olympus Medical Systems. All other authors have nothing to disclose with regard to commercial support.

Received for publication May 26, 2016; revisions received Aug 16, 2016; accepted for publication Oct 13, 2016; available ahead of print Nov 4, 2016.

Address for reprints: Ichiro Yoshino, MD, PhD, Department of General Thoracic Surgery, Graduate School of Medicine, Chiba University, 1-8-1 Inohana, Chuo-ku, Chiba, 260-8670 Japan (E-mail: iyoshino@ faculty. chiba-u.jp).

J Thorac Cardiovasc Surg 2017;153:472-5

$0022-5223 / \$ 36.00$

Crown Copyright (c) 2016 Published by Elsevier Inc. on behalf of The American Association for Thoracic Surgery http://dx.doi.org/10.1016/j.jtcvs.2016.10.021
}

We herein report a novel technique of crossfield intubation using left bronchostomy for the operative management of left carinal pneumonectomy. The case was a 52-year-old female patient. A tumor involving the left main bronchus was revealed on a computed tomography scan (Figure 1, A). Emergent bronchoscopy revealed that the tumor had occluded the left main bronchus (Figure 1, $B$ ) and invaded the carina. Two expandable metallic stents (Ultraflex Tracheobronchial Uncovered Stent System; Boston Scientific Corporation, Natick, Mass) were then inserted in tandem by respirologists (Figure 1,C). The patient was diagnosed pathologically with adenoid cystic carcinoma. We decided to perform carinal pneumonectomy 1 month after the placement of the endobronchial metallic stents (Figure 2, A).

\section{TECHNIQUE}

The patient was placed in the supine position and then was intubated with a normal single lumen tube. A transtracheal endobronchial balloon blocker was inserted through the endotracheal tube and placed in the left main bronchus within the metallic stents. Clamshell thoracotomy was selected to dissect the tumor. Anterior pericardiotomy was performed, which exposed the lower trachea, carina, bilateral main bronchus, and right pulmonary artery. The left hilum was dissected and the left pulmonary vessels were encircled. After the inflation of the endobronchial balloon in the left main bronchus, bronchostomy was performed at the proximal portion of the left lower bronchus (Figure 2, B). A 5.5-mm inner diameter spiral endotracheal tube (Phycon, Tokyo, Japan) was fixed with a purse string suture, and a cross-field ventilation of the entire left lung was then established (Figure 1,D).

The trachea was transected at the 3 rings above the carina, and the right main bronchus was transected at the orifice. The transtracheal endobronchial balloon blocker was then removed and the 2 stumps were sutured on the specimen

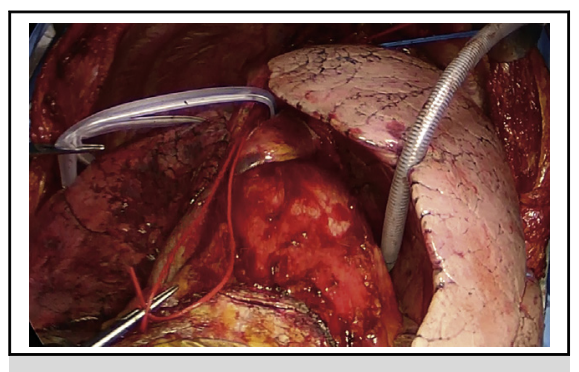

Crossfield ventilation via bronchostomy could maintain a stable anesthetic condition.

Central Message

During left carinal pneumonectomy, bronchostomy to establish cross-field ventilation helps to make operative manipulation easier.

See Editorial Commentary page 476. side to seal the newly established left ventilation system (Figure 2, C). The trachea and right main bronchus were anastomosed with 4-0 PDS (Ethicon Endo-Surgery, Inc, Cincinnati, Ohio; a continuous suture was used for the membranous portion and intermittent stitching was used for the cartilaginous portion; Figure 2, D).

Soon after we started left lung ventilation, the $\mathrm{SpO}_{2}$ decreased to around $80 \%$, and right-side ventilation was required. Banding of the right main pulmonary artery with a vessel loop was effective for maintaining oxygenation during crossfield ventilation $\left(\mathrm{SpO}_{2}>90 \%\right)$ by adjusting the ventilation-perfusion inequality. Despite some sections of the left main bronchus showing very severe adhesion to the posterior pericardium, the left carinal pneumonectomy was completed by transection of the previously dissected vessels (operation period, 6 hours 2 minutes; estimated blood loss, $940 \mathrm{~mL}$; Video 1).

\section{DISCUSSION}

The first successful case of left carinal pneumonectomy was reported in 1969 for adenoid cystic carcinoma arising in the left main bronchus. ${ }^{1}$ As shown in the first

Scanning this QR code will take you to a procedural video.

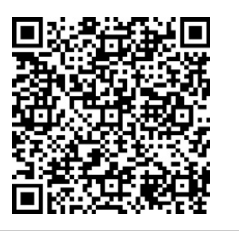



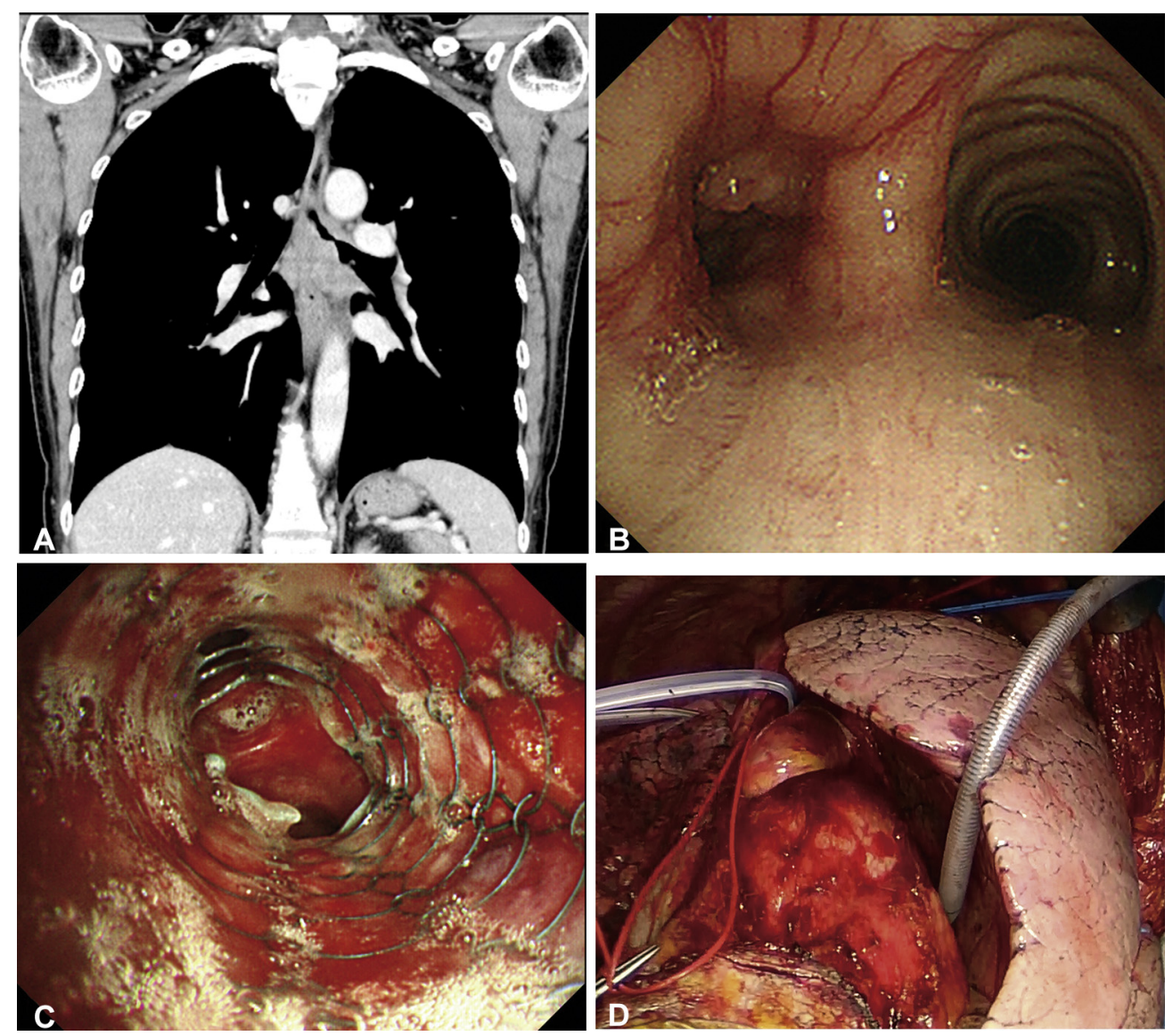

FIGURE 1. A, Chest computed tomography showed a tumor involving the left main stem bronchus and carina. B, Bronchoscopy revealed that the tumor occluded the left main bronchus. C, Two expandable metallic stents were inserted in tandem in the left main stem bronchus. D, A 5.5-mm inner diameter spiral endotracheal tube was fixed with a purse string suture to the proximal portion of left lower bronchus. Crossfield ventilation of the entire left lung was then established.

case, it is common to insert the endotracheal tube into the right main bronchus across the surgical field and to repeat the insertion and remove the endotracheal tube with intermittent ventilation during bronchial anastomosis. ${ }^{2}$ This procedure can be performed safely; however, the surgeon often regards this form of airway maintenance as burdensome.

Several surgical approaches have been reported for left carinal pneumonectomy. Thoracotomy with a posterolateral skin incision is one of the approaches for this procedure ${ }^{3}$; however, in cases with adhesion around the left main bronchus, this approach provides only a limited view of the contralateral bronchus. The clamshell incision approach is known to provide excellent surgical exposure and is reported to have been used for left carinal pneumonectomy. ${ }^{4}$

Crossfield ventilation via bronchostomy is capable of maintaining stable oxygenation and ventilation, and it facilitates the smooth performance of tracheobronchial anastomosis because the lung that is being ventilated is not involved in the reconstruction after the limits of resection have been defined. The application of extracorporeal lung support (ECLS) including cardiopulmonary bypass and extracorporeal membrane oxygenation may be effective for avoiding cross-field ventilation ${ }^{5}$; however, ECLS likely will increase the amount of bleeding during surgery because of the anticoagulation during ECLS, especially in cases with severe adhesion.

We thank Ms Risa Ishimura (Photo Center, Chiba University Hospital) for making illustrations of this procedure.

\section{References}

1. Thompson DT, Doyle JA, Roncoroni AJ. Carinal resection, left pneumonectomy, and right lung anastomosis for adenocystic basal cell carcinoma (cylindroma). Thorax. 1969;24:752-5.

2. Banki F, Wood DE. Techniques of performing left carinal pneumonectomy. $O p$ Tech Thorac Cardiovasc Surg. 2007;12:194-209. 


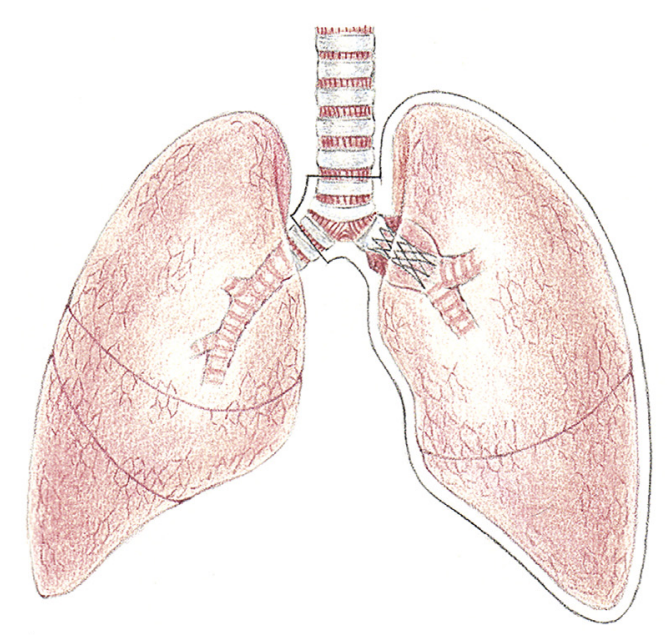

A

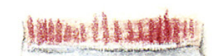

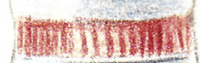

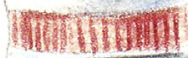

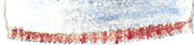

$\rightarrow$ mintminm:

rem

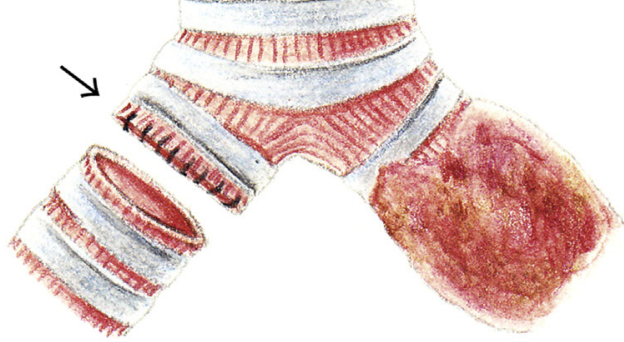

C

FIGURE 2. A, Left carinal pneumonectomy was planned for this patient. B, After inflation of the endobronchial balloon in the left main bronchus, bronchostomy was performed at the proximal portion of the left lower bronchus and a spiral endotracheal tube was fixed with a purse string suture. C, The 2 stumps on the specimen side were sutured to seal the newly established left ventilation system (arrow). D, The trachea and right main bronchus was anastomosed.

3. Kawagoe I, Inada E, Ishikawa S, Matsunaga T, Takamochi K, Oh S, et al. Perioperative management of carinal pneumonectomy: a retrospective review of 13 patients. J Anesth. 2015;29:446-9.

4. Miyazaki T, Yamasaki N, Tsuchiya T, Matsumoto K, Tomoshige K, Abe $\mathrm{K}$, et al. Left sleeve pneumonectomy via a clamshell incision for
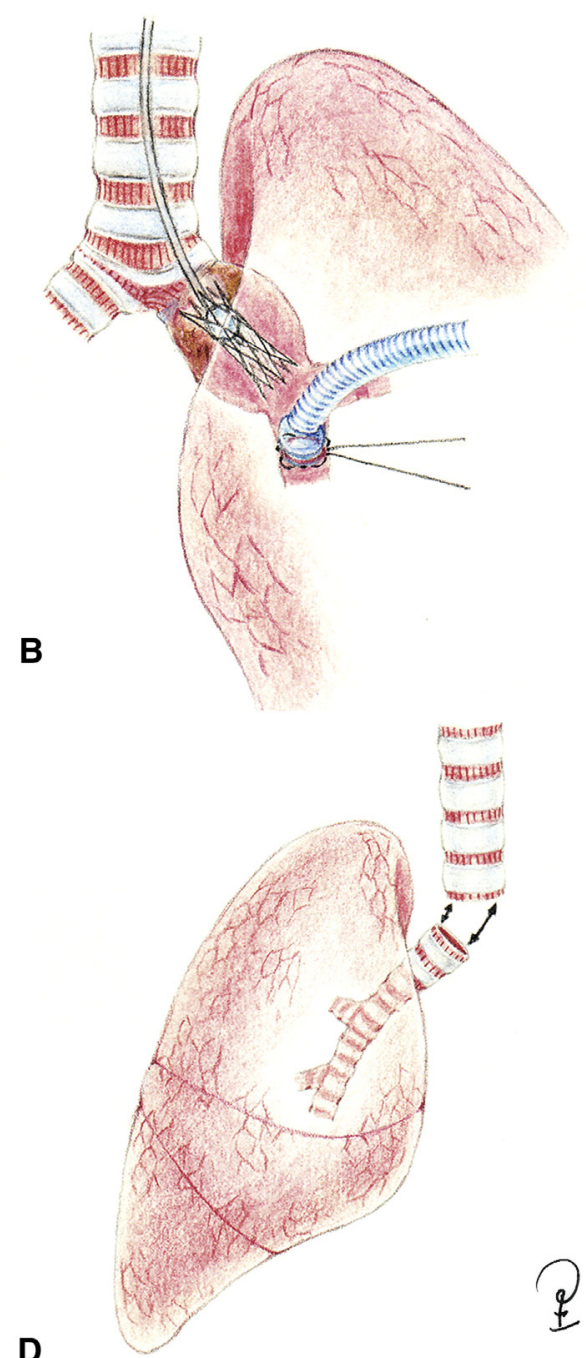


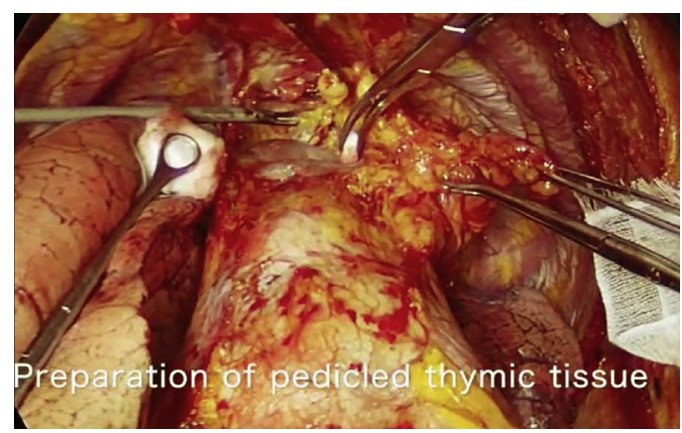

VIDEO 1. The patient was placed in a supine position and approached via a clamshell incision. Pedicled thymic tissue was prepared first, and the left brachiocephalic vein was exposed. Through median pericardiotomy, a mediastinal dissection was performed to expose the great vessels and trachea. The superior vena cava and right main pulmonary artery were encircled. The surgery was started from the left side. After the dissection of the left hilum, bronchostomy was performed at the entrance of the left lower bronchus. The tip of a short-cuff spiral tube (5.5-mm inner diameter) was inserted into the bronchostomy and fixed with a purse-string suture. Crossfield ventilation for the left lung was established with an endotracheal blocker within the left main bronchus via the use of metallic stents. We then moved to the right side. The right hilum was dissected, and an infrahilar pericardial incision was made to mobilize the right hilum. The right main bronchus was transected at one ring from the carina on the peripheral side. After confirmation of right hilum mobilization, the trachea was transected at 3 rings above the carina on the oral side. After transection, the stumps of the specimen side were sutured to maintain the newly established left-side ventilation. During anastomosis between the trachea and right main bronchus, ventilation was dependent entirely on the left lung through the bronchostomy. The membranous portion was sutured with 4-0 PDS, with a continuous suture used for the membranous portion and intermittent stitching for the cartilaginous portion. Banding of the right main pulmonary artery via a vessel loop was helpful for maintaining satisfactory oxygenation $\left(\mathrm{SpO}_{2}>90 \%\right)$ through reduction of ventilation-perfusion mismatch. After the completion of anastomosis, ventilation through the endotracheal tube was resumed, and the right lung was well ventilated without any air leakage. We then moved to the left side. The endobronchial tube for the bronchostomy was removed, and the bronchostomy was closed to minimize contamination. The left pulmonary vessels were then transected. We moved to the deepest portion of the mediastinum to dissect the tumor arising from the left main bronchus. The tumor adhered strongly to the surrounding tissues. The aortic arch and right pulmonary artery were encircled and retracted to maintain the surgical manipulation field. Part of the posterior pericardium also was removed with the tumor because of the severe adhesion. The tracheobronchial anastomosis was wrapped with thymus and anterior mediastinal fat tissue with the use of fibrin glue. The operation duration was 6 hours 2 minutes, and the estimated blood loss was $940 \mathrm{~mL}$. Video available at: http://www.jtcvsonline.org/article/ S0022-5223(16)31398-8/addons. 